\title{
Reações cutâneas secundárias ao uso dos inibidores do receptor de fator de crescimento epidérmico: relato de dois casos
}

\author{
Cutaneous reactions due to the use of epidermal growth factor receptor \\ inhibitors: two case reports
}

\author{
Camila Martins Rodarte ${ }^{1}$ \\ Nadyesda Fagundes Barbosa ${ }^{3}$ \\ Uirá Maira Resende 5
}

\author{
Omar Ali Abdallah ${ }^{2}$ \\ Ludmila de Oliveira Koch ${ }^{4}$
}

\begin{abstract}
Resumo: O aumento da expressão de receptores do fator de crescimento epidérmico (EGFR) está envolvido no estímulo ao crescimento tumoral. Seus inibidores demonstraram eficácia no tratamento de neoplasias de cabeça e pescoço, cólon e pulmão. A inibição do EGFR pode determinar reações cutâneas em mais de 50\% dos pacientes. Em geral, são reversíveis, mas, quando graves, limitam o uso da droga. Lesões papulopustulosas em face e tronco são as mais comuns, além de xerose, alterações ungueais e dos pelos. A intensidade da toxicidade cutânea tem relação direta com a resposta antitumoral. Uma abordagem dermatológica adequada é essencial para dar continuidade à terapia contra o câncer de forma satisfatória.

Palavras-chave: Anticorpos monoclonais; Erupções acneiformes; Receptor do fator de crescimento epidérmico

Abstract: An increase in the expression of epidermal growth factor receptors (EGFR) is involved in the stimulation of tumor development. EGFR inhibitors have shown efficacy in the treatment of neoplasms of the head, neck, colon and lung. EGFR when inhibited can cause cutaneous reactions in more than $50 \%$ of the patients. They are usually reversible, but when severe, limit the use of the drug. Papulopustulars lesions in the face and upper torso are the most common, as well as xerosis, hair and nail changes. There is a direct relationship between the degree of cutaneous toxicity and the antitumoral response. An adequate dermatologic approach is necessary for an effective therapy against cancer.

Keywords: Acneiform eruptions; Antibodies, monoclonal; Receptor, epidermal growth factor
\end{abstract}

\section{INTRODUÇÃO}

Muitas neoplasias têm a expressão aumentada de receptores do fator de crescimento epidérmico (EGFR) que estão envolvidos no estímulo ao crescimento tumoral e resistência aos tratamentos de quimioterapia e radioterapia. Os inibidores desses receptores, os anti-EGFR, já demonstraram eficácia em estudos clínicos em neoplasias de cabeça, pescoço, cólon e pulmão e têm ganhado cada vez mais destaque na oncologia. ${ }^{1,2}$ Entretanto, reações cutâneas, principalmente do tipo acneiforme, ocorrem em mais de 50\% dos pacientes que utilizam os anti-EGFR ${ }^{3}$ e, muitas vezes, são severas, necessitando de redução da dose ou até suspensão do seu uso. Uma abordagem dermatológica adequada é essencial para dar continuidade ao tratamento do câncer de forma satisfatória.

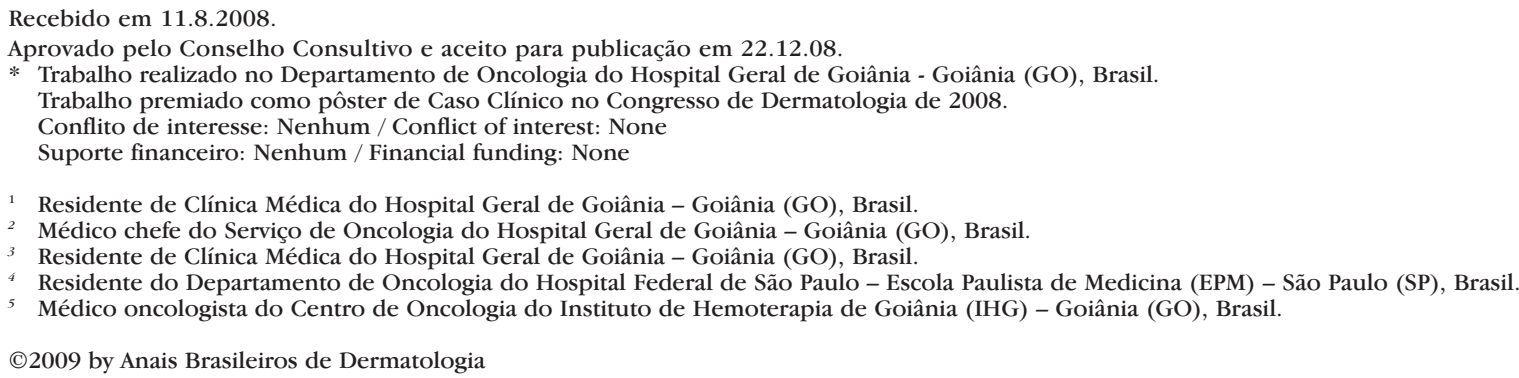




\section{RELATO DE CASOS}

CASO 1: Paciente do sexo feminino, 47 anos, diagnóstico de neoplasia metastática de cólon, apresentou progressão da doença após primeira linha de tratamento quimioterápico. Iniciou uso de cetuximab, anticorpo monoclonal anti-EGFR, apresentando reações cutâneas severas em face, padrão acneiforme, sendo tratada com antibiótico tópico (clindamicina 1\% gel) e agente hidratante (Figura 1), sem redução da dose da medicação. Evoluiu com melhora parcial do quadro, recebendo ainda cinco doses do medicamento com flutuações de melhora e piora do quadro cutâneo.

CASO 2: Paciente do sexo feminino, 85 anos, diagnóstico de neoplasia de pulmão localmente avançada (adenocarcinoma). Iniciado tratamento com erlotinib, medicação oral com ação inibidora da tirosino-quinase do EGFR. Após terceiro mês do início da terapia, evoluiu com lesões pustulosas e ulceradas em membros inferiores (Figura 2) e lesões ungueais, compatíveis com paroníquia (Figura 3). Fez tratamento com antibiótico oral (doxiciclina $100 \mathrm{mg}$ duas vezes ao dia por sete dias) e tópico (clindamicina 1\% gel), com melhora das lesões. Suspensão do erlotinib por outros motivos, evolução sem recorrência das lesões.

\section{DISCUSSÃO}

O EGFR é uma glicoproteína transmembrana expressa, normalmente, em diversos tecidos humanos e está envolvido no controle do crescimento e da proliferação celular. ${ }^{2}$ Muitas neoplasias têm a expressão desregulada e aumentada do EGFR, resultando em proliferação, migração e adesão da célula tumoral,

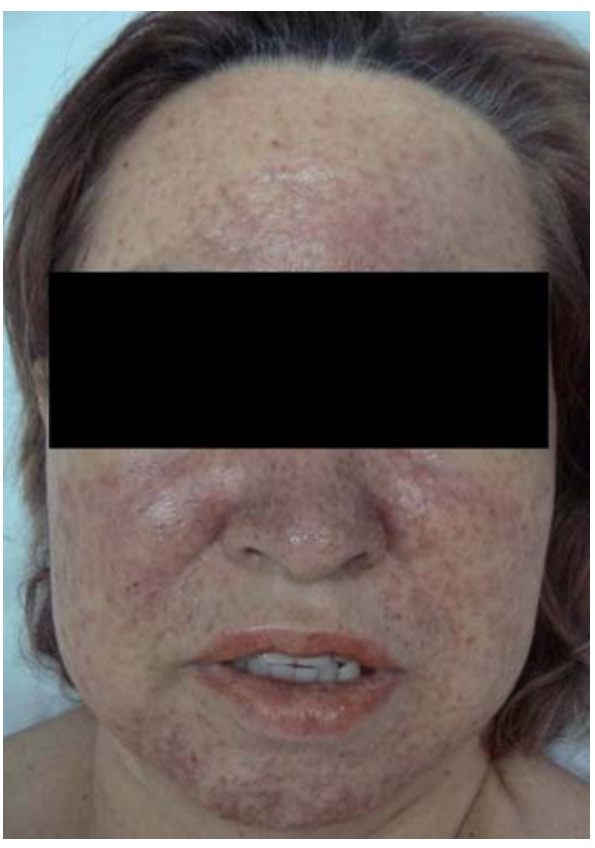

Figura 1:

Pápulas eritematosas disseminadas em face e algumas pústulas após antibioticoterapia tópica

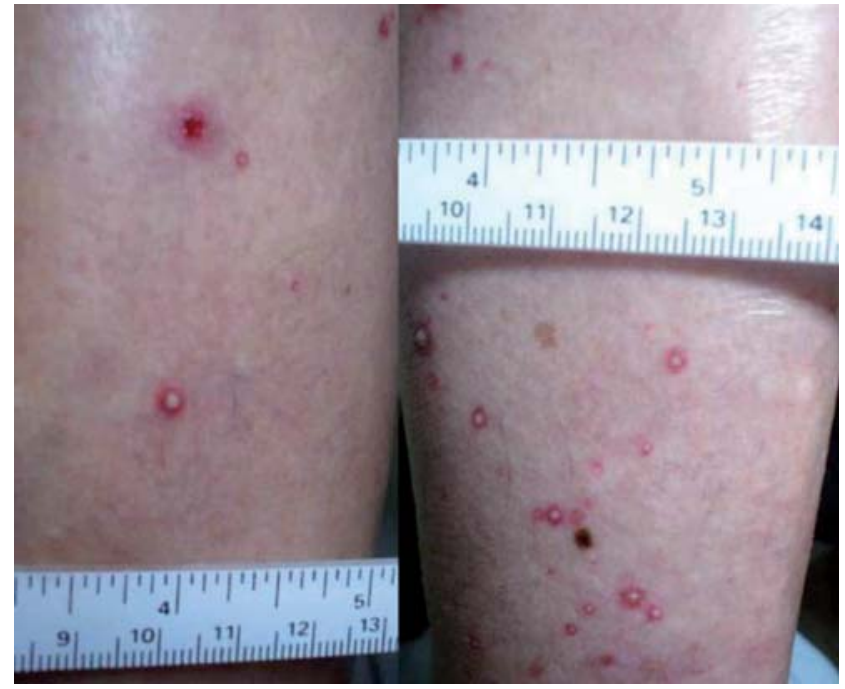

FiguRA 2: Ulcerações e pústulas envoltas por halo eritematoso distribuídas na região anterior e lateral das pernas

além do estímulo à angiogênese e inibição da apoptose. Tais alterações são observadas, principalmente, em neoplasias de cabeça e pescoço, cólon e pulmão e estão relacionadas com progressão da doença, maior chance de metástases, redução da sobrevida e menor resposta à quimioterapia e radioterapia. ${ }^{1,2} \mathrm{~A}$ inibição desses receptores com agentes específicos como cetuximab (anticorpo monoclonal contra o domínio extracelular do receptor) e o erlotinib (molécula inibidora da tirosino-quinase do EGFR) tem demonstrado eficácia no tratamento dessas neoplasias. ${ }^{1,2,4,5}$

O EGFR está normalmente presente nos queratinócitos, glândulas sebáceas e folículos pilosos e, quando inibido, altera a proliferação, a diferenciação e a migração dos queratinócitos, resultando em frequentes reações cutâneas. ${ }^{6}$ Erupções papulopustulosas (reação ou rash acneiforme) em face e tronco, sem a presença de comedões, são as mais observadas e parecem ser uma patologia distinta da acne. Frequentemente se desenvolve nas seguintes fases: eritema e edema (semana 0-1), erupção papulopustular (semana 1-3), formação de crostas (semana 3-5), evoluindo com eritema e telangiectasias (semana 5-8).

Xerose acompanhada de prurido é frequente, principalmente, em membros superiores, inferiores e nas áreas acometidas pelo rash acneiforme, podendo evoluir com lesões secundárias. Também podem ser observadas alterações ungueais, como paroníquia e granuloma piogênico, alterações capilares, como alopécia, tricomegalia das sombrancelhas, hipertricose da face, além de telangiectasias. De modo geral, tais alterações têm início entre a primeira e a terceira 


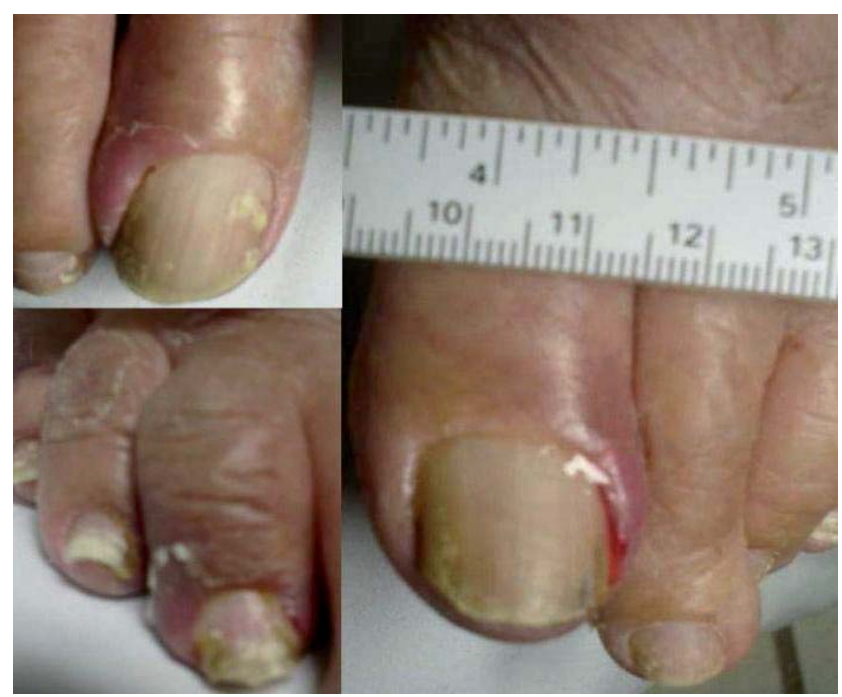

Figura 3: Edema, eritema e descamação periungueal com saída de secreção purulenta e sanguinolenta, compatível com paroníquia

semanas de tratamento. ${ }^{8,9}$ As lesões costumam ser reversíveis e regridem sem sequela, mas, quando graves, podem ser intoleráveis, necessitando de redução da dose ou suspensão da medicação, o que interfere no tratamento do câncer. ${ }^{10}$
Existem evidências concretas de que, quanto maior a intensidade da toxicidade cutânea, melhor a resposta antitumoral e maior a sobrevida. ${ }^{10,1}$ Pacientes com ausência de mutação do gene K-ras ${ }^{11}$ parecem apresentar melhor resposta aos anti-EGFR.

$\mathrm{O}$ tratamento das reações não é bem estabelecido, variando entre os serviços, e depende da intensidade das lesões. ${ }^{2}$ Recomendam-se proteção solar e hidratação da pele com emolientes para todos os pacientes e anti-histamínicos em caso de prurido. Nos casos leves, são usadas medicações tópicas como hidrocortisona $1 \%$ ou clindamicina $1 \%$, duas vezes ao dia. Nos casos moderados, hidrocortisona $1 \%$, clindamicina $1 \%$ ou tacrolimus/pimecrolimus associado com antibioticoterapia oral (doxiciclina $100 \mathrm{mg}$ duas vezes ao dia). Nos casos graves, além das medicações anteriores, indica-se uma dose de metilprednisolona e a redução da dose ou suspensão da terapia com o anti-EGFR. ${ }^{1}$

Os anti-EGFR são drogas novas e seu uso tem ganhado cada vez mais destaque na oncologia. Entretanto, as frequentes manifestações cutâneas, apesar de estarem relacionadas com uma resposta antitumoral melhor, podem limitar seu uso adequado. Há necessidade de mais estudos para garantir uma abordagem mais direcionada da toxicidade cutânea, considerando-se o quanto isso pode interferir na qualidade de vida do paciente e na sua decisão de continuar a terapia antitumoral. 


\section{REFERÊNCIAS}

1. Lynch TJ Jr, Kim ES, Eaby B, Garey J, West DP, Lacouture ME. Epidermal growth factor receptor inhibitor - associated cutaneous toxicities: an evolving paradigm in clinical management. Oncologist. 2007;12:610-21.

2. Lacouture ME, Melosky BL. Cutaneous reactions to anticancer agents targeting the epidermal growth factor receptor: a dermatology-Oncology perspective. Skin Therapy Lett. 2007;12. [Available from: http://www.skintherapyletter.com/2007/12.6/1.html]

3. Agero AL, Dusza SW, Benvenuto-Andrade C, Busam KJ, Myskowski P, Halpern AC. Dermatologic side effects associated with the epidermal growth factor receptor inhibitors. J Am Acad Dermatol. 2006;55:657-70.

4. Jonker DJ, O'Callaghan CJ, Karapetis CS, Zalcberg JR, $\mathrm{Tu} \mathrm{D}, \mathrm{Au} \mathrm{HJ}$ et al. Cetuximab for the treatment of colorectal cancer. N Engl J Med. 2007;357:2040-8.

5. Krause DS, Van Etten RA. Tyrosines kinases as targets for cancer therapy. N Engl J Med. 2005;353:172-87.

6. Fox LP. Pathology and management of dermatologic toxicities associated with anti-EGFR therapy. Oncology (Williston Park).. 2006;20(Suppl 2):26-34.
7. Lacouture ME, Lai SE. The PRIDE (Papulopustules and/or paronychia, Regulatory abnormalities of hair growth, Itching, and Dryness due to epidermal growth factor receptor inhibitors) syndrome. Br J Dermatol. 2006;155:852-4.

8. Busam KJ, Capodieci P, Motzer R, Kiehn T, Phelan D, Halpern AC. Cutaneous side-effects in cancer patients treated with antiepidermal growth factor receptor antibody C225. Br J Dermatol. 2001;144:1169-76.

9. Payne AS, James WD, Weiss RB. Dermatologic toxicity of chemotherapeutic agents. Semin Oncol. 2006;33:86-97.

10. Segaert S, Tabernero J, Chosidow O, Dirschka T, Elsner $\mathrm{J}$, Mancini $\mathrm{L}$ et al. The management of skin reactions in cancer patients receiving epidermal growth factor receptor targeted therapies. J Dtsch Dermatol Ges. 2005;3:599-606.

11. Eng C. K-ras and sensitivity to EGFR inhibitors in metastatic colorectal cancer. Clin Adv Hematol Oncol. 2008;6:174-5.

Como citar este artigo / How to cite this article: Rodarte CM, Abdallah OA, Barbosa NF, Koch LO, Resende UM. Reações cutâneas secundárias ao uso dos inibidores do receptor de fator de crescimento epidérmico: relato de dois casos. An Bras Dermatol. 2009;84(6):667-70. 